\title{
LA PÉRDIDA DE UNA OPORTUNIDAD EN LA JURISPRUDENCIA DE LA CORTE SUPREMA SOBRE JUICIOS INDEMNIZATORIOS DERIVADOS DEL TERREMOTO Y TSUNAMI DE 27 DE FEBRERO DE 2010
}

THE LOSS OF A CHANCE IN THE JURISPRUDENCE OF THE

SUPREME COURT ON INDEMNIFICATION JUDGMENTS

DERIVED FROM THE EARTHQUAKE AND TSUNAMI OF

FEBRUARY 27, 2010

RODRIGO BARRÍA DÍAZ*

\section{RESUMEN}

El presente artículo tiene por objetivo realizar un análisis acerca de la forma en que la teoría de la pérdida de la oportunidad ha sido utilizada por la Corte Suprema de nuestro país para fundamentar la condena al Fisco de Chile en los juicios por indemnización de perjuicios incoados a propósito del fallecimiento de personas a causa del terremoto y posterior tsunami que asolaron el territorio nacional el 27 de febrero de 2010.

Palabras Clave: Pérdida de Oportunidad, Terremoto, Causalidad, Daño.

* Abogado, Licenciado en Ciencias Jurídicas y Sociales de la Universidad de Concepción y Doctor en Derecho, Universidad de Salamanca, España. Profesor de Derecho Civil, Universidad Alberto Hurtado, Santiago, Chile. Correo electrónico: jbarria@uahurtado.cl.

Artículo recibido el 29 de marzo de 2019 y aceptado para su publicación el 13 de junio de 2019. 


\section{ABSTRACT}

The purpose of this article is to analyze the way in which the theory of the loss of a chance has been used by our Supreme Court to support the conviction of the Chilean Treasury in the lawsuits for compensation for damages brought on purpose of the death of people due to the earthquake and subsequent tsunami that devastated the territory of our country on February 27, 2010.

Keywords: Loss of a Chance, Earthquake, Causation, Damage.

\section{INTRODUCCIÓN}

La pérdida de una oportunidad constituye una figura de la responsabilidad civil respecto de cual la doctrina nacional ha manifestado un notorio interés en los últimos años, ${ }^{1}$ a pesar de que en el derecho extranjero ha sido objeto de estudio hace ya varias décadas, lo que en ningún caso significa el agotamiento de su contenido. ${ }^{2}$ Para la dogmática nacional del derecho

\footnotetext{
${ }^{1}$ Algunos ejemplos: BARros, Enrique, Tratado de responsabilidad extracontractual, Editorial Jurídica de Chile, Santiago, 2006, pp. 378-383; TAPIA, Mauricio, "Pérdida de una chance: ¿Un perjuicio indemnizable en Chile?", en Elorriaga, F. (coord.), Estudios de Derecho Civil VII, Abeledo Perrot, Thomson Reuters, Santiago, 2012, pp. 645 y ss.; TAPIA, Mauricio, "Pérdida de una chance. Su indemnización en la jurisprudencia chilena", Revista de Derecho Escuela de Postgrado, 2012, № 2, pp. 251-264; MunitA, Renzo, "La pérdida de una chance. Notas desde una perspectiva comparada", Actualidad Jurídica, 2013, $\mathrm{N}^{\circ} 28$, pp. 395 y ss.; Ríos, Ignacio; SiLva, Rodrigo, Responsabilidad civil por pérdida de la oportunidad, Editorial Jurídica de Chile, Santiago, 2014; Ríos, Ignacio; Silva, Rodrigo, "La teoría de la pérdida de la oportunidad según la Corte Suprema", Revista de Derecho Escuela de Postgrado, 2015, № 7, pp. 165 y ss.; Ríos, Ignacio, “ ¿Quién carga con el peso de la incertidumbre causal?”, en Vidal, Á.; Severín, G.; Mejías, C. (Eds.), Estudios de Derecho Civil X, Thomson Reuters, Santiago, 2014, pp. 861 y ss.

2 Viney, Genevieve; Jourdain, Patrice, Traité de Droit Civil. Les Conditions de la Responsabilité, L.G.D.J, París, 1998, $2^{\mathrm{a}}$ edición, pp. 71-79; Arcos VIEIRA, María Luisa, Responsabilidad Civil: Nexo Causal e Imputación Objetiva en la Jurisprudencia, Thomson Aranzadi, Cizur Menor, 2005, pp. 5560; Medina Alcoz, Luis, La Teoría de la Pérdida de Oportunidad, Thomson Civitas, Cizur Menor, 2007; Vicente Domingo, Elena, "El Daño”, en Busto Lago, J.M.; Reglero Campos, L.F. (Coords.), Lecciones de Responsabilidad Civil, Thomson Reuters - Aranzadi, Cizur Menor, 2013, $2^{\mathrm{a}}$ edición, pp. 90-91; VAN DAM, Cees, European Tort Law, Oxford University Press, Oxford, 2013, $2^{\mathrm{a}}$ edición, pp. 337-342; Deakin, Simon; Johnston, Angus; Markesinis, Basil, Tort Law, Oxford University Press, Oxford, 2013, 7a edición, pp. 238-241; AlPA, Guido, La Responsabilidad Civil. Parte General, Ediciones Legales, Lima, 2016, Vol. 1, pp. 732-737; SteEL, Sandy, Proof of Causation in Tort Law, Cambridge University Press, Cambridge, 2015, pp. 339-369; Green, Sarah, Causation in Negligence, Hart Publishing, Oxford, 2015, pp. 152 y ss.; TurTon, Gemma, Evidential Uncertainity in Causation in Negligence, Hart Publishing, Oxford, 2016, pp. 122 y ss.; Medina Alcoz, Luis, La Responsabilidad
} 
civil no se trata de ninguna manera de un tema desconocido, pero puede sostenerse que durante muchos años no estuvo entre las prioridades de los especialistas, debido principalmente a que la pérdida de la oportunidad cargó por bastante tiempo con una imagen discutida, derivada fundamentalmente, aunque no en forma exclusiva, de la negativa e influyente opinión que sobre los daños eventuales había manifestado Arturo Alessandri en 1943 en su obra De la responsabilidad extracontractual en el derecho civil chileno. ${ }^{3}$ No obstante, en los últimos años se ha observado un incremento de los trabajos dedicados a analizar esta figura, a configurar sus condiciones de aplicabilidad y a promocionar su incorporación al bagaje jurisprudencial, esfuerzo que ha rendido sus frutos, puesto que desde un tiempo a esta parte es posible verificar, y cada vez más visible, su presencia en las decisiones de los tribunales de justicia chilenos en distintas materias entregadas a su conocimiento.

Cuando hablamos de la pérdida de oportunidad, o de la chance, siguiendo el conocido galicismo aceptado por la Real Academia Española de la Lengua, nos referimos, en general, a una situación jurídica consistente en que una persona pierde la posibilidad o expectativa de conseguir o tener un bien, material o inmaterial, una ventaja o un beneficio, debido a la acción u omisión de otro individuo. ${ }^{4}$ La forma de entender a la pérdida de oportunidad en los distintos sistemas jurídicos es diversa, por cuanto existen básicamente dos líneas de inteligencia de la figura. Por una parte, se considera que la pérdida de la oportunidad constituye un daño para quien la experimenta, que consiste en la desaparición de esa oportunidad, lo que no es lo mismo que la pérdida del bien o interés mismo al que se pretendía acceder,

Proporcional como Solución a la Incertidumbre Causal, Thomson Reuters - Civitas, Cizur Menor, 2018, pp. 89-93; Barcellona, Mario, Trattato della Responsabilitá Civile, UTET Giuridica, Torino, 2011, pp. 400-429; WeInRIB, Ernest, "Causal Uncertainty", Oxford Journal of Legal Studies, 2016, vol. $36, \mathrm{~N}^{\mathrm{a}} 1$, pp. 157 y ss.

3 Alessandri, Arturo, De la responsabilidad extra-contractual en el derecho civil chileno, Editorial Jurídica Ediar-Conosur, Santiago, 1983, 2a edición, T. I, pp. 217 y 218. Un análisis de la opinión de este autor en esta materia y cómo ha influenciado a los autores nacionales se encuentra en Ríos y SiLVA, Responsabilidad civil..., cit. (n. 1), pp. 212-216.

${ }^{4}$ El concepto que he utilizado es propio, pero se encuentra en consonancia con otras descripciones de la pérdida de una oportunidad que pueden encontrarse, por ejemplo, en TAPIA, "Pérdida de una chance: ¿Un perjuicio indemnizable en Chile?”, cit. (n. 1), pp. 645-646; Ríos y SiLva, Responsabilidad civil..., cit. (n. 1), pp. 24 y ss.; Steel, cit. (n. 2), p. 339; Medina Alcoz, La Teoría de la Pérdida de Oportunidad, cit. (n. 2), pp. 55-79; JourdaIn, Patrice, Les principes de la responsabilitè civile, Dalloz, 2007, pp. 130-131. 
puesto que la obtención de éste era una situación incierta y aleatoria. ${ }^{5}$ Por la misma razón, cuando se entiende que la oportunidad perdida es un daño, el monto de su reparación no puede equivaler al valor que se espera percibir en caso de efectivamente haber obtenido el beneficio perseguido, sino que su cuantía debe ser evaluada en términos más restringidos. Se trata de una característica de la pérdida de la oportunidad como daño autónomo respecto de la cual existe un consenso generalizado entre los autores. ${ }^{6}$

Desde otro punto de vista se considera que la pérdida de oportunidad en realidad no es un daño en sí mismo, sino que se trata de una situación de daño en la que va envuelto un problema de relación de causalidad. En efecto, en hipótesis de este tipo el problema consiste en que no es posible establecer un vínculo causal entre el hecho que produce la pérdida de oportunidad y la pérdida efectiva del bien, beneficio, ventaja o derecho que se pretendía obtener por el perjudicado, debido al carácter meramente hipotético de esta última situación. Entonces, son dos las posibilidades frente a esta incertidumbre causal: o se desecha la pretensión indemnizatoria, al no comprobarse el nexo de causalidad, siguiendo la regla del "todo o nada" en materia de prueba de la causalidad, o bien se aplica un cálculo probabilístico, de acuerdo al cual la indemnización debe pagarse en un monto reducido en función de la probabilidad que habría tenido el perjudicado de obtener el beneficio en cuestión, de no haber perdido la oportunidad de lograrlo. ${ }^{7}$ Esta última alternativa, en caso de ser finalmente aceptada e implementada funciona, entonces, como un mecanismo que permite sortear la dificultad de comprobación del nexo causal que presenta el ya mencionado sistema binario del "todo o nada", ${ }^{8}$ permitiendo a la víctima la obtención de una indemnización calculada en función de la probabilidad que hubiese tenido de obtener el beneficio que

\footnotetext{
5 Ríos y Silva, Responsabilidad civil..., cit. (n. 1), pp. 91 y ss.; TAPIA, "Pérdida de una chance: ¿Un perjuicio indemnizable en Chile?", cit. (n. 1), p. 645 y ss; Jourdain, cit. (n. 4), pp. 130-131; VINEY y Jourdain; cit. (n. 2), pp. 71 y ss.; TurTon, cit. (n. 2), pp. 145 y ss. Con una visión crítica de esta concepción, Medina Alcoz, La Responsabilidad Proporcional..., cit. (n. 2), pp. 89-93;

6 Ríos y SiLva, Responsabilidad civil..., cit. (n. 1), p. 268; TAPIA, "Pérdida de una chance: ¿Un perjuicio indemnizable en Chile?", cit. (n. 1), pp. 645-647; Medina Alcoz, La Responsabilidad Proporcional..., cit. (n. 2), pp. 89-90; STEel, cit. (n. 2), pp.351-352; Viney y Jourdain; cit. (n. 2), pp. 84-85; MunitA, cit. (n. 1), pp. 437-441, citando doctrina y jurisprudencia francesas..

7 Turton, cit. (n. 2), pp. 122-145; SteEl, cit. (n. 2), pp. 319-322; Ríos y Silva, Responsabilidad civil..., cit. (n. 1), pp. 167 y ss; Medina Alcoz, La Teoría de la Pérdida de Oportunidad, cit. (n. 2), pp. 79 y ss.

8 Medina Alcoz, La Responsabilidad Proporcional..., cit. (n. 2), pp. 90-91.
} 
pretendía si no se hubiese malgastado la oportunidad por el demandado. ${ }^{9}$

A diferencia de esta última concepción de la pérdida de una oportunidad, cuando ésta es entendida como un daño autónomo, en realidad no hay un problema causal que resolver, porque, si bien es cierto que en ese daño también está presente la imposibilidad o extrema dificultad de probar la relación de causalidad entre un hecho y el resultado dañoso que significa la pérdida de una ventaja o beneficio para la víctima, no es menos cierto que sí existe y posiblemente sea más fácil la prueba del nexo causal entre tal hecho y la destrucción de la oportunidad de alcanzar la ventaja o beneficio. ${ }^{10}$

En el derecho extranjero, específicamente en el derecho europeo continental, la suerte de la pérdida de oportunidad es disímil. En aquellos países integrantes de la vertiente germánica (Alemania, Austria y los países escandinavos), el concepto de pérdida de oportunidad es rechazado como un daño y también como un problema de causalidad probable, por la aplicación estricta de la regla del "todo o nada". En tanto que en la línea de países influenciados por el Código Civil de Francia, tales como este último, España y Holanda, su consideración como un daño indemnizable se encuentra actualmente consolidada. Por otra parte, en la familia del common law el derecho inglés la aplica solamente a ciertos grupos de casos, especialmente en lo relacionado con casos de negligencias médicas ${ }^{11}$ y pérdidas financieras. ${ }^{12}$

En nuestro país, la jurisprudencia, a través de la Corte Suprema, ha acogido solamente en años recientes la pérdida de oportunidad, más concretamente y de forma más clara a partir de la sentencia de 20 de enero de 2011, pronunciada en la causa "Ojeda Soto con Servicio de Salud Viña del Mar Quillota", ${ }^{13}$ que reconoció en materia de prestaciones de salud la pérdida de oportunidad de sobrevida a una paciente a quien no se la diagnosticó adecuadamente una dolencia que le provocó la muerte años

\footnotetext{
9 Steel, cit. (n. 2), p. 355.

${ }^{10}$ Por esta razón es que MEDINA ALCOZ, en una mirada severamente crítica de la pérdida de la oportunidad entendida como daño, sostiene que es un expediente que presenta "como verdadero algo que es enteramente falso: que, cuando hay dudas en torno al nexo causal, pero el juicio probatorio arroja una probabilidad nada desdeñable, la víctima sufre la pérdida de un bien distinto, esto es, la pérdida (con conexión causal segura) de la posibilidad de evitar el daño final (de causalidad incierta)". MedINA AlCOz, La Responsabilidad Proporcional..., cit. (n. 2), p. 90. En un sentido parecido, a propósito del actual estado de la pérdida de oportunidad en Francia, comenta SteEL, cit. (n. 2), pp. 337-338.

${ }^{11}$ Nolan, Donal, "Causation and the goals of tort law", en: Robertson, A.; Wu, Tang H. (Eds.), The Goals of Private Law, Hart Publisher, Oxford, 2009, p. 179.

${ }^{12}$ VAN DAM, cit. (n. 2), p. 342.

${ }^{13}$ Corte Suprema, 20 de enero de 2011, rol No 2074-2009.
} 
más tarde. A partir de ese fallo, la teoría de la pérdida de la oportunidad se ha aplicado en diversas materias conocidas por nuestros tribunales de justicia, siendo una de esas materias las reclamaciones indemnizatorias por fallecimientos de personas ocurridos el 27 de febrero de 2010, a causa del terremoto y posterior tsunami que afectó el territorio nacional en esa fecha.

El objetivo de este trabajo es realizar una investigación que exponga cuál ha sido el tratamiento que ha tenido la doctrina de la pérdida de la oportunidad cuando ella ha sido implementada por la Corte Suprema en las sentencias que resuelven juicios indemnizatorios iniciados por familiares de personas fallecidas en el terremoto y posterior maremoto de febrero de 2010 en contra del Fisco de Chile, por la eventual falta de servicio que habría incidido en la muerte de las víctimas. Para emprender esta labor, expondré cuáles son las etapas que es posible observar en la evolución que ha tenido la doctrina de la pérdida de oportunidad en la materia, plasmada en el resultado de un grupo de fallos dictados en estos juicios por la Corte Suprema desde enero del año 2013 hasta marzo de 2019, con el objetivo de entregar una visión general acerca del criterio seguido para resolverlos y cuál ha sido el rol que ha cumplido en ellos esta doctrina. Enseguida, y una vez identificadas las sentencias donde se utiliza esta doctrina, realizaré un análisis crítico de la forma en que la Corte ha abordado la pérdida de la oportunidad y cuáles son las virtudes y defectos que observo en su aplicación.

\section{II.EVOLUCIÓN DE LAS SENTENCIAS DICTADAS POR LA CORTE SUPREMA}

Analizar cuál ha sido el tratamiento que la jurisprudencia nacional ha dado a la pérdida de oportunidad, en el marco de los juicios indemnizatorios por muerte de personas a causa del tsunami del 27 de febrero de 2010, supone necesariamente examinar cuáles han sido los resultados que dichos juicios han tenido y no sólo la teoría en sí misma y aislada de la decisión final, puesto que, como se verá, ambas están indisolublemente relacionadas. Las demandas presentadas por los familiares de personas fallecidas en tales sucesos han tenido destinos diversos, pero lo relevante a efectos de esta investigación es que la evolución que se observa en las decisiones de nuestros tribunales, particularmente la Corte Suprema, se ha dado en forma bastante definida, conforme el transcurso del tiempo y el cambio de opinión de los jueces. Esta característica permite establecer tres etapas muy marcadas, aunque incluso ellas se puedan superponer cronológicamente, constituida cada una por fallos 
que reflejan de manera muy evidente los bruscos cambios de parecer de los sentenciadores respecto a la procedencia de la acción indemnizatoria y de las razones jurídicas para aceptarla o rechazarla.

De este modo, es posible afirmar que en esta materia existen tres fases diferentes, las cuales se individualizan no tanto por su secuencia en el tiempo, sino más bien por el contenido de las sentencias incluidas en ellas. En una primera etapa, la Corte Suprema respaldó la idea de rechazar las demandas de indemnización, fundada básicamente en la ausencia de causalidad entre la falta de servicio de los respectivos organismos del Estado de Chile y el fallecimiento de personas a causa de la catástrofe. Posteriormente, encontramos un segundo momento durante el cual la Corte Suprema decide acoger las demandas deducidas, razonando que en realidad sí existe una relación de causalidad entre la falta de servicio y la muerte de las víctimas, siendo aquella la causa de la segunda. Finalmente, existe una tercera etapa, en que la Corte Suprema prosigue la línea de aceptación de las demandas, pero apoyándose para acogerlas en la doctrina de la pérdida de la chance, entendiendo que la falta de servicio significó para las víctimas ya no la causa de sus fallecimientos, sino que perder una oportunidad de sobrevivir al tsunami. En esta última parte, como se verá, la Corte Suprema afirma que en estos casos existe una incertidumbre causal entre la falta de servicio y la muerte de las personas afectadas, pero como tendré oportunidad de exponer, es posible concluir que termina resolviendo los pleitos en el supuesto que la oportunidad perdida por las víctimas constituye un daño autónomo, que es lo que termina indemnizando.

Desde ya es imprescindible insistir en que el análisis de las sentencias se centrará en el lugar que en éstas ocupa la pérdida de la oportunidad y la forma en cómo ha sido tratada por la Corte Suprema, por lo que la gran mayoría de los fallos corresponden a dicho tribunal. Por otra parte, debo reiterar que en las etapas de esta evolución incide el aspecto cronológico, pero que no es completamente determinante, puesto que sentencias de un determinado contenido se han dictado paralelamente a otras de contenido diverso, aspecto que dice relación con ciertos vaivenes de la Corte en esta materia y que analizaré dentro de este trabajo.

También quiero anotar que en todas estas sentencias existen varias aristas que sería muy interesante analizar en profundidad, como la existencia y contornos de la falta de servicio, la naturaleza del caso fortuito o la existencia y configuración de la culpa de las víctimas, así como aspectos propios de otras disciplinas que inciden en estos fallos, tales como el Derecho Administrativo 
o el Derecho Procesal, pero tal labor excede completamente el objetivo y dimensiones de este trabajo. De modo que cualquier aproximación a los elementos de la responsabilidad extracontractual en juego, como la relación de causalidad o la idea de daño, se hará en función del Derecho Civil y de la necesidad de contextualizar el estudio de la pérdida de oportunidad.

1. Primera etapa: el rechazo de las acciones indemnizatorias por no existir relación de causalidad entre la falta de servicio y el daño

La primera etapa que se observa en la evolución de las sentencias de la Corte Suprema en los juicios indemnizatorios motivados por el tsunami de 2010 corresponde al rechazo a la pretensión de reparación por la muerte de personas en dicho evento, y es una etapa que se inicia con la sentencia de fecha 23 de enero de 2013. ${ }^{14}$ En este fallo la Corte Suprema confirmó la sentencia de la Corte de Apelaciones de Concepción que, a su turno, había rechazado la de primera instancia que acogía la demanda indemnizatoria contra el Fisco. Se trataba de una persona, hijo del actor, que falleció en la ruta Interportuaria cuando se dirigía desde Chiguayante hacia Talcahuano, viaje en el cual fue alcanzado por la ola del tsunami y que había emprendido supuestamente motivado por el aviso radial dado por el Intendente de la Región del Bío-Bío, que desestimaba la ocurrencia del fenómeno. Las cortes desecharon la demanda, puesto que no percibieron la existencia de causalidad entre la actuación del Intendente y la muerte del hijo del demandante, toda vez que se comprobó en el juicio que la víctima decidió partir a Talcahuano antes de la emisión de la entrevista donde la autoridad descartó el maremoto, hecho este último considerado por la Suprema como el fundamento de la demanda (considerando sexto).

A idéntica solución, y basadas en el mismo fundamento jurídico de la ausencia de relación de causalidad en supuestos fácticos similares, llegan dos sentencias de la Corte Suprema, de 29 de abril de $2014^{15}$ y de 4 de octubre de $2016 .{ }^{16}$

En esta primera etapa de la evolución en análisis, el rechazo a la pretensión indemnizatoria trae aparejada la completa ausencia de la doctrina de la pérdida de la oportunidad en el análisis de la Corte Suprema. La Corte

\footnotetext{
${ }^{14}$ Corte Suprema, 23 de enero de 2013, rol N $1250-2012$.

${ }^{15}$ Corte Suprema, 29 de abril de 2014, rol N ${ }^{\circ} 16.920-2013$ y rol N ${ }^{\circ} 16.885-2013$.

${ }^{16}$ Corte Suprema, 4 de octubre de 2016, rol N² 24.306-2016.
} 
aborda el problema causal desde un punto de vista tradicional, aplicando la regla del "todo o nada" para establecer si existió o no un vínculo causal entre el llamado de la autoridad regional a desplazarse libremente debido a la ausencia de tsunami y la muerte de las víctimas, quienes en estos casos habrían actuado por decisión propia, descartándose la relación de causalidad. Al entender el alto Tribunal que no existe nexo causal entre ambos hechos, concluye que no existe responsabilidad del Estado y no analiza siquiera tangencialmente la posibilidad que el fallecimiento se hubiese debido a la pérdida de oportunidad alguna.

Como la teoría de la pérdida de oportunidad está completamente ausente del criterio judicial en esta etapa, no es mucho lo que puede decirse en relación a ella como motivo central de este trabajo. Pero es inevitable comentar que, si se la analiza conforme a un entendimiento riguroso de la causalidad, estas sentencias son irreprochables. La comprobada iniciativa personal de las víctimas que las llevó a realizar un viaje sin contar con información oficial que confirmara o desestimara un posible tsunami sin duda descarta cualquier influencia de la posterior declaración radial del Intendente del Bío-Bío en su actuación. En consecuencia, el problema causal que siempre subyace en la pérdida de oportunidad no se dio en este caso y eso facilitó considerablemente la acertada labor de los sentenciadores, facilidad que, como veremos enseguida, no siempre se presentó en juicios posteriores. ${ }^{17}$

\section{Segunda etapa: la Corte Suprema acoge las demandas indemnizatorias por ser la falta de servicio la causa de los fallecimientos}

Esta segunda etapa se caracteriza, tal como lo anticipa el título del epígrafe, porque en ella se observa que las sentencias dictadas por la Corte Suprema reconocen la existencia de una falta de servicio de parte del Estado de Chile, la que a juicio del máximo tribunal constituye la causa de la muerte de las personas afectadas por el tsunami de febrero de 2010. Al existir relación de causalidad entre esa falta de servicio y los fallecimientos, la Corte accede a conceder indemnización de perjuicios a favor de los actores. Dentro de esta etapa es posible incluir a las sentencias de 18 de diciembre

\footnotetext{
${ }^{17}$ Cabe mencionar que la sentencia de la Corte Suprema de 28 de junio de 2018, rechazó una demanda de indemnización de perjuicios por considerar los sentenciadores que en el caso concreto no existió falta de servicio atribuible al Fisco de Chile. Corte Suprema, 28 de junio de 2018, rol N 31.757-2017.
} 
de $2013 ;{ }^{18} 7$ de junio de $2016 ;{ }^{19} 27$ de julio de $2017 ;{ }^{20} 31$ de julio de $2017 ; ;^{21}$ 28 de agosto de $2017 ; ;^{22} 21$ de noviembre de $2017 ; ;^{23} 12$ de diciembre de $2017 ;{ }^{24} 29$ de diciembre de $2017 ;{ }^{25} 26$ de marzo de $2018 ;{ }^{26} 3$ de octubre de $2018 ;{ }^{27} 4$ de diciembre de $2018 ;{ }^{28}$ y 18 de marzo de $2019 .{ }^{29}$ Especialmente relevante resulta el primero de los fallos mencionados, puesto que es la primera sentencia que acoge la pretensión indemnizatoria en nuestro país por desgracias suscitadas por el cataclismo del año 2010.

Antes de detallar los rasgos más relevantes del contenido de dichas sentencias, es útil mencionar que algunas de ellas (18 de diciembre de 2013, 27 de julio de 2017, 28 de agosto de 2017, 29 de diciembre de 2017, 26 de marzo de 2018, 3 de octubre de 2018, 4 de diciembre de 2018 y 18 de marzo de 2019), corresponden a juicios iniciados por muertes ocurridas en la Región del Bío-Bío, y en los que la falta de servicio alegada por los demandantes consistió en la errónea información entregada por vía radiofónica a la población en orden a descartar la posibilidad de ocurrencia de un tsunami. Otras sentencias también se refieren a hechos desarrollados en esa región, pero consistiendo la falta de servicio en la omisión de cualquier aviso de ocurrencia del tsunami ( 21 de noviembre de 2017 y 12 de diciembre de 2017). Las otras dos sentencias (7 de junio de 2016 y 31 de julio de 2017), en tanto, corresponden a procesos iniciados por la muerte de personas que, al tiempo del maremoto, vivían en la isla Robinson Crusoe, perteneciente al archipiélago Juan Fernández, y en los cuales la falta de servicio alegada consistió en no haber dado el Estado, a través de los organismos competentes, ningún tipo de advertencia a los lugareños acerca de la llegada de las olas que arrasaron la isla.

Precisadas las diferencias anteriores, cabe destacar que este grupo de

\footnotetext{
${ }^{18}$ Corte Suprema, 18 de diciembre de 2013, rol N ${ }^{\circ} 1.629-2013$.

${ }^{19}$ Corte Suprema, 7 de junio de 2016, rol N³2.262-2015.

${ }^{20}$ Corte Suprema, 27 de julio de 2017, rol N 68.818-2016.

${ }^{21}$ Corte Suprema, 31 de julio de 2017, rol N 88.986-2016.

${ }^{22}$ Corte Suprema, 28 de agosto de 2017, rol No 97.661-2016.

${ }^{23}$ Corte Suprema, 21 de noviembre de 2017, rol N ${ }^{\circ} 100.695-2016$.

${ }^{24}$ Corte Suprema, 12 de diciembre de 2017, rol N 172-2017.

${ }^{25}$ Corte Suprema, 29 de diciembre de 2017, rol N 97.668-2016.

${ }^{26}$ Corte Suprema, 26 de marzo de 2018, rol N ${ }^{\circ} 10.165-2017$.

${ }^{27}$ Corte Suprema, 3 de octubre de 2018, rol N 42.539-2017.

${ }^{28}$ Corte Suprema, 4 de diciembre de 2018, rol N ${ }^{\circ} 45.305-2017$.

${ }^{29}$ Corte Suprema, 18 de marzo de 2019, rol N 4185-2018.
} 
sentencias presenta ciertos aspectos comunes que es importante destacar. En primer lugar, todas ellas asumen la existencia de una falta de servicio de parte del Estado, sea que se trate de la entrega de información incorrecta, sea que se trate de una completa ausencia de información. Por otra parte, la Corte desestima la existencia de caso fortuito como eximente de responsabilidad favorable al demandado, así como la posible culpa de las víctimas. Finalmente, y esto a propósito de las sentencias concernientes a las muertes ocurridas en la Región del Bío-Bío, específicamente en la ciudad de Talcahuano, la relación de causalidad fue establecida en base a presunciones, fundadas en elementos probatorios tales como los dichos de testigos de oídas o informes periciales de la Policía de Investigaciones de Chile.

En este último grupo de sentencias, la determinación de la causalidad por esta vía obedece a que, como se recordará, el fundamento de las demandas se encuentra en que las víctimas siguieron la recomendación del aviso radial dado por el intendente regional que descartaba el peligro de tsunami, lo que en definitiva resultó ser falso. Debido a este lamentable error comunicacional muchas personas dejaron los lugares donde se habían refugiado o permanecieron en sitios de peligro. Sin embargo, en los casos tratados en este apartado no fue posible demostrar con la certeza que exige la regla del "todo o nada" que esas personas efectivamente escucharon la comunicación de la máxima autoridad regional y que, además, esa fue la razón por la que se expusieron a las marejadas que les provocaron la muerte.

Ahora bien, para los efectos de este trabajo lo más relevante de las decisiones judiciales en comento dice relación con el nexo de causalidad. En todas las sentencias que he incluido aquí se da por establecida la existencia de una relación de causalidad entre la falta de servicio (información errónea en el caso de Talcahuano o ausencia de información en la isla Robinson Crusoe) con la muerte de las personas afectadas, ya sea porque esa información incorrecta los indujo a adoptar medidas que vulneraron su seguridad personal o porque nunca llegaron a tener posibilidad alguna de hacer algo para evitar las fatales consecuencias del tsunami. En otras palabras, en estas sentencias la Corte Suprema atribuye a los comportamientos positivos o negativos de autoridades y organismos estatales la capacidad causal de llevar a la muerte por inmersión a las víctimas del maremoto.

El inconveniente que plantea este razonamiento de la Corte Suprema es bastante evidente. Cuando los sentenciadores afirman que de no haber sido las víctimas mal informadas (como ocurrió en Talcahuano) o privadas de toda información (como fue el caso de la isla Robinson Crusoe y también 
en la localidad de Dichato, en la región del Bío-Bío) habrían salvado sus vidas, están asumiendo que esas personas efectivamente habrían tomado las medidas adecuadas para salvarse y que, además, lo habrían logrado. Sin embargo, tal asunción es solo especulativa. Al tratarse de hechos futuros e inciertos no es plausible asegurar que los afectados habrían hecho algo para salvarse, que lo que habrían hecho hubiese sido lo correcto y adecuado y que, finalmente, habrían salido airosos, o bien, que no hubiese intervenido ninguna otra circunstancia que les hubiese impedido evitar el maremoto. La Corte Suprema yerra al atribuir mérito causal en las muertes de esas personas a la falta de servicio estatal, puesto que, en rigor, esa falta de servicio lo que provocó fue una mala decisión por parte de las víctimas o que éstas no pudieran tomar decisión alguna. Pero la causa efectiva de la muerte de estas personas fue el fenómeno natural al que se vieron expuestas y nada puede asegurar que de haber sido oportuna y correctamente informados habrían hecho o habría ocurrido lo necesario para salvarse.

Entonces, es visible cuál es el error que afecta a todas estas sentencias de la Corte Suprema desde el punto de vista de la relación de causalidad. En ellas se lleva a cabo una aplicación equivocada de la teoría de la equivalencia de las condiciones, por cuanto no resulta posible, a la luz de esta fórmula, afirmar que de haber recibido las víctimas del tsunami la información correcta en el momento oportuno habrían sobrevivido, tal como equivocadamente razona la sentencia de 27 de julio de 2017 en su considerando vigésimo quinto cuando señala que "... sin ese llamado a la calma y si, por el contrario, se hubiese informado la posibilidad de un maremoto en los términos del fax recibido en la ONEMI a las 4.07 horas de la madrugada, el resultado fatal no se habría producido".

Resulta claro que la aplicación estricta de la más certera de las teorías conocidas para establecer la causalidad material es insuficiente cuando se trata de resolver el problema causal en esta clase de siniestro. Más adelante los jueces de la Corte Suprema modificaron su razonamiento y encontraron una nueva solución que se plasmó en sus sentencias, dando lugar a la tercera etapa que se observa en el curso evolutivo de las decisiones en esta materia.

3. Tercera etapa: la Corte Suprema acoge las demandas indemnizatorias por constituir la falta de servicio la pérdida de una oportunidad para las víctimas

En lo que considero es una tercera etapa en el desarrollo de esta 
clase de juicios se observa la continuación de la tendencia a la concesión de las reparaciones económicas solicitadas por los actores. En general, la Corte Suprema sigue entendiendo que el 27 de febrero de 2010 existió un comportamiento por lo menos insuficiente de parte de los organismos del Estado competentes, que derivó en una situación propicia para el fallecimiento de las víctimas a causa del maremoto ocurrido en esa fecha. Por lo tanto, tal falta de servicio constituye la base fáctica y jurídica para decidir en este sentido. Sin embargo, es posible constatar que existe un problema causal muy difícil de abordar, puesto que, o bien la causalidad no existe, lo que implica rechazar las pretensiones indemnizatorias (como ocurrió en los casos de la primera etapa) o presumir el nexo causal (como sucede en los casos de la segunda etapa); o bien, como ocurre en la segunda etapa, se vincula causalmente la falta de servicio en forma directa con la muerte de las personas en el tsunami, solución que, como ya he comentado, adolece de una muy criticable falta de rigurosidad desde el punto de vista de la técnica jurídica.

Sin embargo, desde hace algún tiempo es posible verificar la continuidad de sentencias favorables a los demandantes en contra del Fisco de Chile, pero con un cambio sustancial en la fundamentación de las decisiones. Ese cambio consiste en que, para la Corte Suprema, la falta de servicio por parte de las entidades estatales no es ya la causa de las muertes en el tsunami, sino que constituye solamente el motivo de la pérdida de una oportunidad para las víctimas de haber sobrevivido a la catástrofe.

Esta nueva etapa en el criterio de la Corte Suprema se inaugura con la sentencia del 9 de noviembre de $2017^{30}$ y comprende, hasta la fecha de elaboración completa de este trabajo, a los fallos de 16 de noviembre de $2017 ; 3^{31} 17$ de enero de $2018 ; 3^{32} 17$ de abril de $2018 ;{ }^{33} 8$ de noviembre de $2018 ;{ }^{34}$ y 21 de enero de $2019 .{ }^{35}$ A continuación, haré una reseña de las seis sentencias en que, hasta la fecha, la Corte Suprema se ha pronunciado a propósito de demandas de esta naturaleza reconociendo la idea de la pérdida de oportunidad como fundamento para conceder la indemnización solicitada

\footnotetext{
${ }^{30}$ Corte Suprema, 9 de noviembre de 2017, rol N ${ }^{\circ} 12.169-2017$.

${ }^{31}$ Corte Suprema, 16 de noviembre de 2017, rol N 4.658-2017.

${ }^{32}$ Corte Suprema, 17 de enero de 2018, rol N 5.094-2017.

${ }^{33}$ Corte Suprema, 17 de abril de 2018, rol N $18.225-2017$.

${ }^{34}$ Corte Suprema, 8 de noviembre de 2018, rol N 871-2018.

${ }^{35}$ Corte Suprema, 21 de enero de 2019, rol N 40.166-2017.
} 
a los actores, para, enseguida, plantear mis comentarios a la forma y en los términos que lo ha hecho.

(3.1) La primera sentencia dentro de este grupo es la del 9 de noviembre de 2017, que la Corte Suprema pronunció a propósito de un recurso de casación en el fondo deducido en contra del fallo de la Corte de Apelaciones de Santiago ${ }^{36}$ que confirmó la sentencia del Vigésimo Segundo Juzgado Civil de la misma ciudad, ${ }^{37}$ en la causa "Escalona y otros con Fisco de Chile", en que los tribunales mencionados acogieron una demanda de indemnización de perjuicios por falta de servicio presentada por setenta y cuatro personas debido al fallecimiento de otras diecinueve en distintas zonas geográficas del país. Los jueces de instancia indicaron que la falta de servicio de las autoridades involucradas, Servicio Hidrográfico y Oceanográfico de la Armada de Chile (SHOA) y la Oficina Nacional de Emergencias (ONEMI), consistió en no emitir la alerta de tsunami con posterioridad al terremoto del 27 de febrero de 2010, a pesar de contar con información en ese sentido. Para los sentenciadores, tal omisión constituyó para las víctimas "la pérdida de una oportunidad, la que en el caso de autos corresponde a la pérdida de la posibilidad de sobrevida". Este criterio fue aceptado y confirmado por la sentencia de la Corte Suprema en comento.

Enseguida, en la misma sentencia la Corte Suprema manifestó, a propósito de la impugnación por parte del Fisco de lo resuelto en las instancias en cuanto a la existencia de relación de causalidad entre la falta de servicio y la muerte de las víctimas directas del tsunami, lo siguiente en el considerando undécimo: "es necesario enfatizar que los sentenciadores no establecen el vínculo de causalidad entre la falta de información y la muerte o afectación de las personas, sino que expresamente señalan que la omisión en que incurren los organismos pertenecientes a la organización del Estado, privó a las víctimas de su oportunidad de poner a resguardo su vida". Posteriormente, en el considerando décimo tercero, señala que "si bien la certidumbre sobre la relación causal es difícil de establecer, por lo que en estos regímenes de responsabilidad, en la mayoría de los casos sólo será posible efectuar una estimación de la probabilidad de que el daño se deba a un hecho u omisión, por el cual el demandado deba responder, lo cierto es que en el caso concreto, por cierto, existen dificultades para establecer el vínculo

\footnotetext{
${ }^{36}$ Corte de Apelaciones de Santiago, 18 de enero de 2017, rol No 8013-2016.

${ }^{37}$ Vigésimo Segundo Juzgado Civil de Santiago, 27 de abril de 2016, rol C-21.111-2013.
} 
causal, atendido los grados de incertidumbre que se presentan; sin embargo, este escollo se soslaya al atender al hecho que genera la responsabilidad, esto es la omisión de comunicar la alerta de tsunami. Así, acertadamente los sentenciadores acuden a la teoría de la pérdida de la chance".

Finalmente se afirma en la sentencia que "no es posible asumir la falta de relación de causalidad esgrimida por el recurrente, toda vez que en caso alguno los sentenciadores han señalado que el vínculo de la omisión es en relación a la muerte, pues es una obviedad que la muerte se relaciona directamente con un hecho de la naturaleza".

En esta sentencia la opción de la Corte Suprema por la teoría de la pérdida de oportunidad como explicación para la condena indemnizatoria es expresa y clara, consistiendo la falta de servicio en la omisión de la alerta oportuna de ocurrencia del tsunami y la oportunidad perdida en la imposibilidad de estas personas de salvar su vida por la falta de ese aviso. Además, realiza una importante modificación a la línea argumentativa que venían utilizando la sentencias que acogieron las demandas indemnizatorias, puesto que aclara que el vínculo causal no existe entre la falta de información de ocurrencia del tsunami y las muertes, porque estas últimas se debieron al maremoto. Afirma el fallo que en casos de este tipo solo existe una probabilidad de que la falta de servicio sea el origen de los decesos, lo que constituye una incertidumbre causal de difícil solución, la que la Corte Suprema encuentra en la teoría de la pérdida de la chance. Desde este punto de vista la sentencia avanza en remediar las deficiencias técnicas en el análisis de la causalidad que sufrían las resoluciones anteriores a esta.

Sin embargo, no puede dejar de anotarse que el razonamiento de la Corte es importante, pero en cierta forma contradictorio, porque da a entender en su planteamiento que el origen de la opción por la teoría de la pérdida de oportunidad se encuentra en un problema de naturaleza causal para, enseguida, solucionarlo a través de la estimación de la misma como un daño, confirmando la sentencia de primera instancia, que la había considerado en esa misma naturaleza. Esto queda demostrado por lo que expresa el considerando décimo tercero del fallo, según el cual "en el caso concreto, el vínculo de causalidad, se relaciona estrechamente con la teoría en análisis, pues aplicando las ideas expuestas en los considerandos anteriores se concluye que la relación causal se vincula con la circunstancia de privar a las víctimas de una oportunidad de poner a resguardo su vida, cuestión que podrían efectivamente haber realizado si hubiesen recibido la información de riesgo de tsunami oportunamente". 
Queda claro de estas expresiones que la relación de causalidad, en criterio de la Corte Suprema, no une la falta de servicio con la muerte de las personas, sino con la pérdida de oportunidad de haber salvado su vida, la que debe entenderse como el daño indemnizable. En otras palabras, lo que la sentencia parece querer decir es que el problema de causalidad que se presenta en supuestos de esta clase es el de determinar con qué daño se vincula causalmente la falta de servicio. Y el daño no sería otro que la oportunidad perdida de salvar la vida.

Ahora bien, como ya he dicho, lo recién anotado constituye una innovación meritoria en la solución de esta clase de juicios indemnizatorios, pero sin duda introduce una dosis de inconsistencia desde el momento que no aclara cuál es la postura de la Corte frente a uno de los aspectos de la doctrina de la pérdida de la oportunidad más discutido, como lo es la naturaleza de la oportunidad perdida. ${ }^{38}$ Como se verá a propósito de las siguientes sentencias, el problema no se diluye en la medida que la Suprema reincide en el uso de la doctrina.

Otro rasgo que se debe mencionar y que también constituye, a mi juicio, una falencia del fallo dice relación con la cuantificación de la indemnización, que es lo mismo que hablar de la cuantificación de la oportunidad perdida. Como ya sabemos, si cualquier tribunal se decanta por la teoría de la pérdida de la oportunidad en un caso específico debería realizar un procedimiento de cálculo de la indemnización que estará determinado por la naturaleza jurídica que le atribuya a aquella: si considera que la oportunidad perdida es un daño, debe atribuirle un valor, que nunca puede ser mayor que el daño final sufrido; si la entiende como un problema de causalidad entre el hecho culpable y el daño sufrido por la víctima, debe realizar un cálculo que determine qué proporción del daño final constituye la chance perdida.

Pues bien, ni en ni uno ni en otro sentido la Corte lleva a cabo el procedimiento matemático adecuado que se supone conlleva recurrir a la teoría de la pérdida de la oportunidad. En efecto, la Corte Suprema se limitó a confirmar las sentencias de instancia, donde se afirmó, especialmente en la sentencia de primera instancia, que la determinación del valor de la oportunidad perdida corresponde a los jueces, sin indicar con base a qué

\footnotetext{
${ }^{38}$ Con esta actitud la Corte Suprema incurre en la actitud denunciada por algunos autores ya mencionados, como Medina Alcoz, La Responsabilidad Proporcional..., cit. (n. 2), p. 90, y Steel, cit. (n. 2), pp. 337-338, en orden a que la doctrina de la pérdida de la oportunidad es utilizada en realidad como un mecanismo de escape frente a la imposibilidad o extrema dificultad de probar la relación de causalidad entre el hecho dañoso y la pérdida o lesión del beneficio, ventaja o derecho de la víctima.
} 
criterios debe hacerse ese cálculo ni cómo incide en el mismo la naturaleza jurídica de la pérdida de la oportunidad. En este sentido, lo que hizo la sentencia del juzgado civil fue conceder a los actores una indemnización por el daño moral que les significó la muerte de sus familiares, determinada de acuerdo a criterios que la propia sentencia explicita, tales como los grados de cercanía familiar, las vinculaciones derivadas de las relaciones de convivencia y en la natural afección que se produce por la pérdida de un ser querido (considerando quincuagésimo segundo).

Sin duda que la falta de una metodología de cálculo del valor de la oportunidad perdida en las distintas sedes deja trunca la meritoria labor emprendida por estos tribunales para explicar el fundamento jurídico que debe emplearse al responsabilizar al Fisco de Chile. Y es justamente lo que la sentencia de la Corte Suprema, y las de instancia que confirma, terminan haciendo: encontrar una justificación técnicamente mucho más sólida que la de atribuir a los servicios estatales la muerte de las personas en el tsunami, pero se detienen ahí, omitiendo llevar adelante la medición del valor de la oportunidad perdida para, a partir de ese hito, calcular el monto de la indemnización para los actores. Es decir, la implementación de la teoría de la pérdida de la oportunidad en esta sentencia termina siendo desafortunadamente incompleta, carencia que reaparecerá en los fallos posteriores.

(3.2) La segunda sentencia es de fecha 16 de noviembre de 2017, y en ella la Corte Suprema invalidó de oficio la sentencia de la Corte de Apelaciones de Concepción en la causa "Lefiqueo con Fisco", ${ }^{39}$ que había rechazado la demanda de indemnización de perjuicios interpuesta ante el fallecimiento del marido de la actora, en Isla Mocha, Provincia de Arauco, ${ }^{40}$ quien era recolector de algas y que se encontraba pernoctando en una construcción de material ligero cercana a la playa cuando fue alcanzado por el tsunami posterior al terremoto. Lo especial de esta sentencia es que en ella no se recurre claramente a la teoría de la pérdida de la oportunidad, aunque de su texto es posible extraer su utilización.

En este caso, la Corte Suprema consideró que existió falta de servicio de parte de los organismos estatales, consistente en que estos "desplegaron un servicio de prevención deficiente y no ajustado a los protocolos vigentes respecto de un hecho posible en una zona vulnerable, resultando evidente

\footnotetext{
${ }^{39}$ Corte de Apelaciones de Concepción, 5 de octubre de 2016, rol N³01-2016.

40 Tercer Juzgado Civil de Concepción, 30 de octubre de 2015, rol N 1.098-2014.
} 
que no se desarrollaron con eficacia las labores de prevención y coordinación que el ordenamiento jurídico le había encomendado ante situaciones de catástrofes".

Lo llamativo de esta sentencia es que al momento de establecer la relación de causalidad entre la falta de servicio y la muerte del cónyuge de la demandante, manifiesta en el considerando vigésimo primero que: "en materia de prevención o preparación de catástrofes la certidumbre sobre la relación causal es difícil de establecer, por lo que en estos regímenes de responsabilidad en la mayoría de los casos sólo será posible efectuar una estimación de la probabilidad de que el daño se deba a un hecho o, como sucedió en este caso, al incumplimiento de un deber de prevención y educación eficaz y eficiente, por el cual el demandado deba responder. Si el ejercicio de la actividad de recolección de algas, u otras especies, en algunas zonas de la Isla Mocha era una actividad conocida de la autoridad, aquella estaba llamada a regularla, controlarla o determinar, al menos en forma somera, las condiciones de ejercicio y, advertir de los riesgos de su desarrollo en áreas especialmente peligrosas o expuestas a un fenómeno natural previsible como el terremoto y el subsecuente maremoto, de forma que la ausencia de aquella regulación coloca el resultado dañoso en directa relación con la falta atribuida".

Entonces, en esta parte la sentencia considera que la falta de despliegue de un sistema de prevención eficaz fue la causa directa e inmediata de la muerte y no solamente una oportunidad perdida por la víctima que le hubiese permitido salvarse. Sin embargo, con posterioridad la misma sentencia, en el considerando vigésimo cuarto, al analizar la procedencia de fuerza mayor, señala que: "La omisión de aquella obligación no ha estado amparada por la exculpación del terremoto y maremoto del 27 de febrero de $2010 \mathrm{y}$, de la infracción de aquella es que se deriva la responsabilidad del Estado para con la víctima en este caso, quien, de haber sido advertido, preparado, regulado, capacitado y enseñado, habría estado en condición de adoptar medidas más sofisticadas de preparación que le hubieran permitido tener la opción de salvar su vida". De este comentario aparece que, a pesar de no haberse considerado en forma expresa la teoría de la pérdida de oportunidad como fundamento para acoger la demanda, la Corte parece estimar que lo que existió en este caso fue la destrucción de la posibilidad de sobrevivencia para la víctima, la que hubiese podido lograrlo de haber recibido la educación y haber contado con la infraestructura necesaria para enfrentar eventos de esta naturaleza. 
Es evidente que existe una contradicción en la forma que la sentencia plantea la configuración del daño y la relación de causalidad entre aquel y la falta de servicio, lo que no contribuye a clarificar el tratamiento de ambos requisitos de la responsabilidad extracontractual ni el de la teoría de la pérdida de la oportunidad en este caso. Pero la mención a la "opción de salvar su vida" de que fueron privadas las víctimas me inclina a entender que, en este caso, existe una pérdida de oportunidad derivada de la falta de servicio, más allá de lo poco prístinas que resultan ser las expresiones empleadas por los sentenciadores. A esto debe agregarse el considerando vigésimo quinto, que señala en lo pertinente que el Estado debió haber asumido una actividad de prevención "de forma de haber otorgado a la víctima la posibilidad cierta (de) adoptar resguardos más elaborados que le hubieran otorgado una chance efectiva y cierta de evitar las consecuencias dañosas reseñadas en esta causa".

Ahora bien, debo mencionar que la sentencia en comento adolece de omisiones similares a las presentes en la sentencia de 9 de noviembre de 2017, en cuanto a que no contiene una toma de posición de la Corte Suprema acerca de si considera a la pérdida de oportunidad como una forma de daño autónoma o bien como un problema de relación de causalidad entre la falta de servicio y la muerte de la víctima. Además, en relación íntima con lo recién expresado, carece de un procedimiento de cálculo del daño hecho en función precisamente de la naturaleza jurídica de la oportunidad perdida. Este déficit se reitera en todas las sentencias posteriores que acogen a esta teoría para solventar los problemas que presenta la determinación de la responsabilidad del Estado en este tipo de juicios indemnizatorios.

(3.3) Una tercera sentencia de la Corte Suprema es de fecha 17 de enero de 2018. En ella, el tribunal invalidó de oficio la sentencia de la Corte de Apelaciones de Concepción, ${ }^{41}$ que había confirmado la sentencia de primera instancia dictada en la causa "Pinto Flores con Fisco", ${ }^{42}$ la que, a su vez, rechazó la demanda interpuesta por los actores debido al fallecimiento de un grupo de personas en el sector de Mina Costa, comuna de Lebu, en la Región del Bío-Bío, acogiendo la excepción de caso fortuito invocada por el Fisco. La Corte Suprema desestimó el caso fortuito, y al igual que en el caso anterior, estimó la existencia de una falta de servicio en la ausencia de

\footnotetext{
${ }^{41}$ Corte de Apelaciones de Concepción, 18 de octubre de 2016, rol No 70-2016.

42 Tercer Juzgado Civil de Concepción, 20 de octubre de 2015, rol N 1.325-2014.
} 
medidas de prevención destinadas a anular o morigerar las consecuencias negativas de fenómenos naturales como un terremoto o un tsunami. La diferencia con la sentencia anterior está en que, al momento de vincular causalmente la falta de servicio con la muerte de las personas involucradas, la Corte sí defendió en este caso de forma expresa la tesis de la pérdida de oportunidad. Así, en el literal S de la sentencia de reemplazo se anotó lo siguiente: "Es preciso esclarecer, sin embargo, que el mérito de los antecedentes aparejados al proceso no permite asentar de manera categórica e inconmovible que existe un vínculo causal entre dicha falta de servicio y los fallecimientos puesto que la prueba rendida es insuficiente para demostrar que sus muertes derivan, de manera directa y necesaria, de la actuación negligente atribuida al demandado. Empero, los mismos antecedentes comprueban de manera concluyente que, si bien no es posible establecer dicha relación causal, el negligente proceder de los funcionarios del Estado, en cuanto no se implementaron planes de prevención o de capacitación, no se instaló señalética idónea ni se delimitaron vías de escape y zonas seguras, privó a las víctimas, sin duda alguna, de la oportunidad de luchar dignamente por su vida. En efecto, los antecedentes descritos demuestran con nitidez que la ausencia de las regulaciones descritas, así como la falta de las acciones concretas de educación a la población mencionadas, las despojaron de cualquier oportunidad, aun de la más mínima, de enfrentar el evento de la naturaleza de que se trata de manera adecuada, previniendo y disminuyendo, por ende, los riesgos que el mismo comportaba, de manera que de no haber mediado la negligencia descrita todas las personas que se hallaban en la playa "El Diezmo" podrían haber adoptado las providencias de autocuidado imprescindibles y con ello, eventualmente, haber salvado su vida". Inmediatamente la sentencia realiza un análisis de la pérdida de oportunidad, con cita de la opinión de diversos autores. Nuevamente la oportunidad perdida para los fallecidos fue la de salvar su vida si hubiese existido de parte de los organismos del Estado políticas de prevención y preparación a todo nivel para enfrentar fenómenos sísmicos.

(3.4) Enseguida, encontramos la sentencia de 17 de abril de 2018, pronunciada en la causa "Arriagada Sepúlveda con Fisco". Este juicio nace de una demanda interpuesta por un grupo de personas debido al fallecimiento de nueve familiares a causa del tsunami que asoló, en este caso, el sector de Isla Orrego, isla fluvial ubicada en el río Maule, en la zona de Constitución. En este caso la Corte Suprema corroboró lo afirmado por el juzgado civil en 
cuanto a que existió una falta de servicio consistente en omitir las medidas preventivas que pudieron evitar los fallecimientos, lo que demuestra una conducta deficiente de los entes estatales. Enseguida, reiteró la idea de que en materia de prevención de catástrofes la certidumbre sobre la relación causal es difícil de establecer, por lo que en la mayoría de los casos sólo es posible efectuar una estimación de la probabilidad de que el daño se deba a cierto hecho o, como sucedió en este caso, al incumplimiento de deberes de prevención y de salvamento, por los que el demandado debe responder. Por lo tanto, el mérito de los antecedentes aparejados al proceso no permitió asentar, de manera categórica e inconmovible, que existió un vínculo causal entre dicha falta de servicio y el fallecimiento de las personas que se encontraban en Isla Orrego. Posteriormente señala la sentencia que "no obstante, los mismos antecedentes comprueban de manera concluyente que, si bien no es posible establecer dicha relación causal, el negligente proceder de los funcionarios del Estado, en cuanto no se implementaron planes de prevención o de capacitación, no se instaló señalética idónea ni se realizaron labores de salvamento con medios navegables adecuados, privó a las víctimas, sin duda alguna, de la oportunidad de luchar dignamente por sus vidas", para pasar a hacer expresamente un diseño de la pérdida de oportunidad de acuerdo a lo escrito por diversos autores nacionales y extranjeros.

(3.5) Finalmente, corresponde mencionar a las sentencias de 8 de noviembre de 2018 y 21 de enero de 2019, en las que la Corte Suprema confirmó las respectivas sentencias de la Corte de Apelaciones de Talca, ${ }^{43}$ pronunciándose a favor de la pretensión de los actores en juicios iniciados contra el Fisco de Chile por el fallecimiento de personas a causa del tsunami de 27 de febrero de 2010 que asoló la localidad de Curanipe, provincia de Cauquenes, en la Región del Maule, quienes se encontraban acampando en ese lugar.

En estas sentencias la Corte Suprema sigue la línea del fallo de 16 de noviembre de 2017, en el sentido que vuelve a utilizar ideas algo ambiguas para identificar el daño que se vincula causalmente con la falta de servicio, pero con algunos cambios en la expresiones empleadas, que son lo suficientemente relevantes como para ayudar a decantarse más

\footnotetext{
${ }^{43}$ Corte de Apelaciones de Talca, 20 de noviembre de 2017, rol º 1.899-2016, y 8 de junio de 2017, rol No 1.304-2016.
} 
decididamente por la idea de que la Corte considera que en los casos resueltos existió una pérdida de oportunidad de sobrevivencia para las víctimas. Así, en los considerandos vigésimo sexto y vigésimo quinto, respectivamente, de ambas sentencias, se señala que la falta de servicio de los organismos estatales, consistente en no adoptar una batería de medidas dirigidas a prevenir o, al menos, disminuir los efectos devastadores de fenómenos como un tsunami, significó para las personas que acampaban a la orilla del mar en la localidad de Curanipe y que finalmente fallecieron, "una pérdida de la chance de haber podido salvar su vida" y que "el Estado tuvo que haber desplegado toda una actividad eficiente de prevención...de forma de haber otorgado a las víctimas la posibilidad cierta de adoptar resguardos más elaborados que le hubieran otorgado una chance más efectiva y cierta de evitar las consecuencias dañosas reseñadas en esta causa".

\section{COMENTARIOS}

A partir del contenido de estas sentencias resulta posible realizar algunos comentarios comunes a todas ellas, respecto de la pérdida de oportunidad tal como ella ha sido tratada en esta materia por parte de los tribunales nacionales:

1. En primer lugar, y desde un punto de vista general, mi opinión es que este grupo de sentencias contribuye a la consolidación jurisprudencial de la pérdida de oportunidad, la que, como mencioné en un principio, tiene una vida sumamente reciente en nuestra jurisprudencia y cuya mayor aplicación se ha dado en ámbitos diferentes al estudiado en este trabajo. ${ }^{44}$ Estamos hablando de seis fallos de la Corte Suprema, pronunciados entre noviembre de 2017 y enero de 2019, un lapso relativamente breve, en los que la idea de la pérdida de una oportunidad para salvar la vida es acogida y aplicada por la Corte, incluso en algún caso de forma hasta intuitiva, como pareciera que ocurre en la sentencia de 16 de noviembre de 2017.

2. Esta línea favorable a la teoría de la pérdida de oportunidad constituye una modificación de los criterios anteriormente seguidos por la Corte para condenar al Fisco al pago de indemnización. Ello, por cuanto en las sentencias que se vienen pronunciando desde la primera, de diciembre de ${ }^{44}$ TAPIA, "Pérdida de una chance. Su indemnización en la jurisprudencia chilena", cit. (n. 1), pp. 251-
264. 
2013, hasta aquella de noviembre de 2017, siempre se resolvió sobre la base de que las omisiones atribuidas a los organismos estatales como falta de servicio, eran la causa directa y necesaria de la muerte de personas. Entonces, las seis sentencias comentadas no solo implican una forma de consolidación en nuestros tribunales de la teoría de la pérdida de oportunidad, sino que también una modificación de la línea de pensamiento en torno a cómo deben resolverse las demandas de indemnización de perjuicios originadas en el tsunami de 2010.

Ahora bien, es útil tener presente que esta etapa de aceptación e implementación de la teoría de la pérdida de la oportunidad por la Corte Suprema no necesariamente puso término a la etapa anterior de concesión de indemnizaciones con base en una relación de causalidad determinada entre la falta de servicio y la muerte de las víctimas. Si se revisa las fechas de ambos grupos de sentencias se puede comprobar que, siendo la primera sentencia que aplica la teoría de la pérdida de la oportunidad del 9 de noviembre de 2017, con posterioridad a ella se han dictado siete sentencias favorables que siguen la otra línea de razonamiento, teniendo la más reciente fecha 18 de marzo de 2019, es decir, habiendo transcurrido más de un año desde aquella. Por lo tanto, es posible sostener que ambos criterios en torno a cómo deben resolverse los problemas causales en materia de daños causados por el tsunami de 2010 se superponen y se han aplicado simultáneamente en el mismo período, lo que demuestra que el establecimiento del nexo de causalidad en esta clase de evento ha resultado ser un problema complejo de resolver al interior de la Corte Suprema.

Esta volatilidad en los criterios que adopta la Corte Suprema para resolver un asunto concreto no es necesariamente algo nuevo o extraño para quienes están familiarizados con los fallos del Alto Tribunal, pero no deja de llamar la atención que la diferencia de criterios exista aun cuando todas estas sentencias tienen su origen en la Tercera Sala de la Corte. Una posible explicación puede encontrarse en una visión más bien pragmática que tienen los sentenciadores en cuanto a la forma en que deben ser resueltos los juicios indemnizatorios nacidos del sismo del año 2010, aspecto que abordaré más adelante en este trabajo.

En consecuencia, si bien insisto en mi idea que los juicios de reparación nacidos por muertes ocurridas en el maremoto de 2010 son un camino que ha servido para contribuir a la consolidación jurisprudencial de la teoría de la pérdida de la oportunidad, lo cierto es que la inconsistencia que muestra la Corte Suprema en sus sentencias no permite asegurar que en adelante todos 
los juicios de esta índole se van a resolver en base a ella, sino que resulta posible imaginar que todavía se dicten fallos que basen la responsabilidad del Estado en haber causado este la muerte de las personas involucradas debido a la actuación deficiente de sus organismos.

3. Cuando la Corte introduce la pérdida de oportunidad como uno de los fundamentos para decidir los recursos interpuestos, entiende que esta es, desde un punto de vista conceptual, una respuesta a un problema de causalidad. Como se observa en todos los fallos mencionados, la Corte, antes de recurrir a la teoría de la pérdida de oportunidad, sostiene que en estos casos la existencia de una falta de servicio no se encuentra en relación directa y necesaria con la muerte de las personas, la cual tiene su origen en un fenómeno de la naturaleza, como lo es el tsunami que afectó a nuestras costas en 2010, sino con la privación de las víctimas de una oportunidad de poner a resguardo sus vidas. Asimismo, es común a todas las sentencias el reconocimiento de la dificultad que significa establecer la relación de causalidad en este tipo de eventos, debido al alto grado de incertidumbre que presentan, lo que lleva a que en la mayoría de esta clase de juicios solo sea posible realizar una estimación de la probabilidad de que el daño se deba a un cierto hecho u omisión. Finalmente, recordemos que la sentencia de 9 de noviembre de 2017, la primera dictada siguiendo la doctrina de la pérdida de la oportunidad en esta materia, admite en el considerando décimo tercero lo difícil que es establecer en esta clase de juicios la relación de causalidad, razón por la cual solo es posible hacer una estimación de la probabilidad que el daño se deba a un hecho u omisión, pero que "este escollo se soslaya al atender al hecho que genera la responsabilidad, esto es la omisión de comunicar la alerta de tsunami. Así, acertadamente los sentenciadores acuden a la pérdida de la chance".

De aseveraciones como las anotadas aparece de manera bastante clara que, para la Corte Suprema, el punto de partida para la aplicación de la teoría de la pérdida de la oportunidad lo constituye la preexistencia de un severo problema de precisión del nexo causal entre un determinado hecho dañoso y el perjuicio experimentado por la o las víctimas. En nuestro tema, uno y otro extremo están constituidos por la falta de servicio y las muertes de personas en el tsunami de 2010 por falta de información acerca de su ocurrencia, información defectuosa o insuficiencia de medidas de prevención y mitigación de los efectos perniciosos del fenómeno.

Sin duda, no puede dejar de reconocerse el mérito de la Corte Suprema en estas sentencias, en un doble sentido. En primer lugar, los fallos admiten 
las dificultades probatorias que subyacen en los casos de personas fallecidas a causa del tsunami de 2010. Como ya he mencionado antes, en todos los supuestos que han sido sometidos al conocimiento y decisión de nuestros tribunales nos encontramos frente a fallecimientos de personas debidos a una causa muy concreta, la ocurrencia de un maremoto lo suficientemente devastador como para generar destrucción material y la muerte de las víctimas. Lo que ocurre es que esas personas se vieron expuestas a ese evento debido a que no tuvieron información acerca del mismo o tal información resultó ser defectuosa, o bien, se encontraban en lugares carentes de medidas de seguridad. Pero desde un punto de vista estrictamente probatorio es posible concluir y demostrar que estas últimas circunstancias constituyen un servicio mal prestado de parte de los organismos y servicios fiscales, que llevó a las víctimas a adoptar desafortunadas decisiones, pero en ningún caso es posible probar que la falta de servicio condujo a la muerte a esas personas, porque es imposible saber lo que ellas hubiesen hecho con la información apropiada o si las medidas de prevención adoptadas hubiesen sido efectivas.

El segundo sentido en que cabe alabar el razonamiento de la Corte Suprema se refiere al cuestionamiento implícito de su propio criterio implementado en otras sentencias en orden a dar por comprobada la causalidad entre las muertes y la falta de servicio, criterio que es, a mi juicio, equivocado y debería ser descartado por el Alto Tribunal. A pesar de esto ya hemos visto que se trata de un punto de vista que no puede darse por desechado por los jueces de la Corte Suprema ante la aparición de fallos relativamente recientes que han respaldado esa toma de posición.

4. Lo expresado en el numeral anterior debería hacernos afirmar que la Corte Suprema ha optado por entender en este grupo de sentencias que conceptualmente la teoría de la pérdida de la oportunidad es la solución a un problema de prueba de la relación de causalidad, en virtud de la cual debe asumir la labor de establecer de acuerdo a criterios de proporcionalidad cuál es el valor que la falta de servicio ha significado, porcentualmente, en la producción del daño final. ${ }^{45}$ Como está claro que causalmente la falta de servicio no es la razón del perjuicio final, sino solo un factor que ha tenido

\footnotetext{
45 Anotemos que la idea del uso de la doctrina de la pérdida de una oportunidad como forma de enfrentar los problemas de incertidumbre de la relación de causalidad más que como indemnizar un daño autónomo es la forma de entender esta figura generalmente predominante en la órbita del common law. En este sentido, por ejemplo, Nolan, cit. (n. 11), pp. 179-187; GreEN, cit. (n. 2), pp. 152 y ss.; Turton, cit. (n. 2), pp. 132 y ss; Deakin; Johnston; Markesinis, cit. (n. 2), p. 239; Munita, cit. (n. 1), p. 402. También se entiende en este sentido, BARros, cit. (n. 1), p. 379, nota 19.
} 
incidencia en que el daño ocurra, los tribunales involucrados debieron haber emprendido un trabajo destinado a precisar matemáticamente cuál ha sido la proporción en que la falta de servicio influyó en el daño final y en base a ese cálculo determinar el monto de la indemnización. Es lo que corresponde hacer en este escenario de acuerdo a la doctrina nacional y comparada. ${ }^{46}$

Sin embargo, en el conjunto de sentencias que acogen la teoría de la pérdida de la oportunidad, lo que podemos considerar como el escenario ideal en realidad no se verifica. En efecto, del análisis de estos fallos se puede concluir que lo que ellos disponen es que el daño que debe indemnizarse consiste en la falta de oportunidad de las víctimas para salvar su vida. Por ejemplo, en la cronológicamente primera sentencia del grupo, de 9 de noviembre de 2017, luego de anotar que los sentenciadores de instancia han recurrido a la teoría de la pérdida de la chance, señala la Corte Suprema en el considerando vigésimo tercero que “...el vínculo de causalidad, se relaciona estrechamente con la teoría en análisis, pues...se concluye que la relación causal se vincula con la circunstancia de privar a las víctimas de una oportunidad de poner a resguardo su vida, cuestión que efectivamente podrían haber realizado si hubiesen recibido la información de riesgo de tsunami oportunamente". Y agrega este considerando que "en efecto, la omisión de la entrega oportuna de la información solo puede relacionarse con la pérdida de la oportunidad de alejarse de las zonas de riesgos antes de la llegada de las olas que determinan la muerte o afectación de las personas..." Entonces, si la relación de causalidad vincula hecho dañoso con perjuicio, lo que en el caso concreto se traduce en un nexo entre la falta de servicio y una oportunidad perdida de las víctimas para sobrevivir, entonces no queda sino entender que el daño es la pérdida de la oportunidad y no la muerte de las víctimas a la que debería relacionarse en forma proporcional la falta de servicio, si lo entendemos estricta y exclusivamente como un problema causal. ${ }^{47}$

Esta característica que he observado en el fallo aludido se replica en las sentencias posteriores que acogen la teoría de la pérdida de la oportunidad, aunque en términos no tan explícitos. En ellas la Corte Suprema más

\footnotetext{
${ }^{46}$ Medina Alcoz, La Responsabilidad Proporcional ..., cit. (n. 2), pp. 89-90; WeinRiB, cit. (n. 2), pp. 157-158; TurTon, cit. (n. 2), pp. 140-145; VineY y Jourdain; cit. (n. 2), pp. 84-85; TAPIA, "Pérdida de una chance: ¿Un perjuicio indemnizable en Chile?”, cit. (n. 1), pp. 655-657; Ríos y SiLva, Responsabilidad civil..., cit. (n. 1), pp. 268 y ss.

${ }^{47}$ De hecho, la sentencia de la Corte Suprema de 9 de noviembre de 2017 fue pronunciada en una causa en que la sentencia de primera instancia había declarado expresamente que la pérdida de oportunidad es una forma de daño y la indemnización fue otorgada para reparar ese daño.
} 
bien constata que los hechos sometidos a juicio configuran una hipótesis de pérdida de oportunidad, pero no califica en términos expresos a la oportunidad perdida como un elemento que deba ser estimado dentro del análisis causal o bien como un daño autónomamente indemnizable.

El problema que plantea este análisis que hace la Corte Suprema es de coherencia. En rigor, sostener que la pérdida de la oportunidad es la solución a un problema de incerteza causal implica relacionar un hecho (falta de servicio) con una consecuencia dañosa (muerte de las víctimas). Como ya hemos visto que esa relación causal no existe, y así lo reconoce la Corte Suprema, si queremos imponer responsabilidad extracontractual al demandado (Fisco) es necesario hacer el cálculo proporcional al que he aludido, con el objetivo de establecer qué porcentaje de probabilidad de supervivencia significaba para las víctimas la oportunidad perdida. Esta regla constituye una excepción a las reglas tradicionales de prueba de la causalidad, que en ordenamientos jurídicos como el nuestro se rige por la regla del "todo o nada", lo que implica que el nexo causal debe ser probado sin margen de dudas, puesto que, de no ser así, faltará un requisito de la responsabilidad extracontractual y la demanda indemnizatoria deberá ser desestimada.

Pero si entendemos, como he demostrado que hace la Corte Suprema, que la pérdida de una oportunidad es un daño autónomo que han experimentado las víctimas del tsunami, consistente en la destrucción de una oportunidad de sobrevivir a ese desastre natural, resulta que la relación de causalidad se verifica entre el hecho (falta de servicio) y daño (oportunidad perdida), ${ }^{48}$ y en este caso no es posible hablar de que la teoría soluciona un problema de causalidad, porque esa causalidad existe y une ambos extremos que se encuentran demostrados en el proceso. Por lo tanto, lo que los tribunales deberían hacer en este caso es admitir la existencia del nexo causal entre falta de servicio y pérdida de oportunidad y valorar esta última como el daño autónomo que consideran que es.

En otras palabras, estimar a la pérdida de una oportunidad como daño en sí misma, que es lo que hace la Corte Suprema, no presupone un problema causal, porque la causalidad existe y se verifica entre falta de servicio y la pérdida de una chance. El verdadero problema causal solo existe si se entiende que el daño no es la oportunidad perdida, sino que las muertes en el maremoto, las que basan su origen en la falta de servicio que significó a

48 TAPIA, “Pérdida de una chance: ¿Un perjuicio indemnizable en Chile?”, cit. (n. 1), pp. 653-655; Munita, cit. (n. 1), p. 405; Viney y Jourdain; cit. (n. 2), pp. 79-80. 
las víctimas no tener la posibilidad de salvarse y que debe ser medida de acuerdo a criterios propios de la causalidad probabilística.

Entonces, el defecto de coherencia que le atribuyo al razonamiento de la Suprema está directamente vinculado con el planteamiento que hace el tribunal. Si se afirma que la pérdida de oportunidad dice relación con la incerteza causal, entonces debe entenderse como un problema solucionable a través de las reglas de la causalidad probabilística. Pero si se entiende que la pérdida de oportunidad es un daño autónomo, entonces no puede afirmarse, como lo hace el considerando décimo tercero de la sentencia de 9 de noviembre de 2017, que la teoría de la pérdida de la chance es la salida a una cuestión causal, porque la relación de causalidad sí existe y se manifiesta entre la falta de servicio y la oportunidad perdida. Desde ese punto de vista no es criticable que la Corte pueda asumir una u otra posición, sobre todo si se considera que en el derecho comparado ambas formas de entender la pérdida de oportunidad tienen algún grado de recepción. Tampoco me parece criticable -por el contrario, creo que es sumamente positivo-, que las sentencias admitan desde el inicio de su análisis que la base de la aplicación de la teoría consiste en un problema de causalidad material. Pero un adecuado uso de las reglas técnicas obliga a sugerir una mayor congruencia en la implementación de los diversos aspectos de la pérdida de una oportunidad, con miras a una futura correcta aplicación de la misma.

5. Ahora bien, ya sea que la Corte Suprema considere que la pérdida de oportunidad es la respuesta a un problema causal o un daño en sí mismo, en todas las sentencias analizadas ha incurrido en un error metodológico para llegar a cuantificar el daño. Es más, quizás sería lo correcto afirmar que no existe método alguno de cálculo en las sentencias comentadas, considerando que ellas entienden que existe una pérdida de oportunidad que debería influir en la avaluación de las indemnizaciones.

Por una parte, cuando la pérdida de oportunidad es vista como un problema exclusivamente causal, consistente en que no existe certeza en que si la víctima hubiese tenido la oportunidad hubiera podido evitar el daño, en el derecho comparado se sostiene que debe ser aplicada la llamada causalidad probabilística, consistente en que como no existe la seguridad que la oportunidad hubiera evitado el daño, sino que solo hay una probabilidad de que ello ocurriese, la Corte debería haber realizado una operación matemática encaminada a establecer cuál habría sido el porcentaje de esas probabilidades, y así fraccionar la causalidad de acuerdo al porcentaje estimado. Esto tiene incidencia en la cuantificación del daño, ya que, al no 
haber certeza de la causalidad, sino solo una probabilidad, resultaría que la indemnización debería ser considerada en proporción al porcentaje de probabilidad de que la falta de servicio hubiese ocasionado el daño. ${ }^{49}$

Por otra parte, si la pérdida de oportunidad se analiza como un daño autónomo, que es lo que en definitiva parecen hacer los tribunales de nuestro país, sabemos que los jueces deben atribuirle a través de cálculos razonados un valor a esa oportunidad, el cual necesariamente debe ser inferior al de la ventaja perdida. ${ }^{50}$

Sin embargo, en las sentencias que he comentado eso no ocurre, puesto que no solo no existen tales operaciones matemáticas, sino que la indemnización parece entregarse completa, sin deducciones de ningún tipo, como una suma global a consecuencia de una relación de causalidad solo probable o de un daño de menor entidad al que podría haberse evitado. Esto es sumamente relevante para una implementación coherente de esta teoría, porque la circunstancia de constituir la oportunidad perdida una incidencia causal o un daño en sí misma finalmente tiene relevancia para el cálculo de la indemnización de perjuicios, el que se hará en función de la convicción de los tribunales en uno u otro sentido. Pero para que ello suceda es necesario que los sentenciadores expongan conforme a qué criterio aritmético establecen el valor de la oportunidad perdida y posteriormente utilicen dicho valor en el cálculo indemnizatorio.

En cambio, la actual situación de los tribunales chilenos en los juicios por muertes ocurridas en el tsunami de 2010 es otra, como se desprende de las sentencias examinadas en este trabajo. Los sentenciadores, luego de explicar que en los decesos producidos por el maremoto no existió relación de causalidad con la falta de servicio, sino con la oportunidad destruida, lo que, como ya he señalado antes, debe hacernos entender que esta es el daño a indemnizar, no llevan a cabo ningún procedimiento matemático destinado a cuantificar el valor real de esa oportunidad perdida, sino que condenan al Fisco al pago de una indemnización por daño moral en favor del o los actores por el significado emocional que para ellas ha tenido la muerte de las personas.

De lo anterior se desprenden las siguientes ideas acerca de la cuantificación indemnizatoria en estos fallos:

\footnotetext{
${ }^{49}$ Medina Alcoz, La Teoría de la Pérdida de Oportunidad, cit. (n. 2), pp. 106 y ss.

${ }^{50}$ Ríos y Silva, Responsabilidad civil..., cit. (n. 1), pp. 272 y 273.
} 
a. La teoría de la pérdida de la oportunidad es empleada por nuestros tribunales para calificar jurídicamente los hechos centrales del juicio indemnizatorio y para separar lo que es la muerte de las personas por el tsunami de la pérdida de una oportunidad a causa de la falta de servicio, entendiendo, acertadamente, que se trata de circunstancias diferentes.

b. A partir de lo anterior, se deduce que los sentenciadores consideran que la relación de causalidad no se da entre la falta de servicio y los decesos, sino entre aquella y la oportunidad perdida. Con esta aclaración los tribunales inicialmente admiten que en la pérdida de oportunidad subyace un problema causal, pero terminan resolviéndolo atribuyendo a la pérdida de oportunidad la naturaleza de daño autónomo, lo que se desprende en forma más bien implícita del énfasis puesto por los fallos, especialmente y en forma más clara el de 9 de noviembre de 2017, en orden a que el nexo de causalidad une la deficiente actuación estatal con la desvanecida oportunidad de haber sobrevivido al maremoto.

c. No obstante lo dicho, las sentencias no cuantifican el valor de la oportunidad perdida para así establecer el monto de la indemnización, sino que en los seis fallos analizados los tribunales conceden una indemnización por el daño moral sufrido por los demandantes a causa de la muerte de sus seres queridos. Pero esto es completamente cuestionable, porque de las sentencias queda claro que el Fisco no tuvo injerencia en la muerte de las víctimas del tsunami, sino en que estas perdieran una oportunidad de sobrevivir a esa catástrofe. En otras palabras, el cuasidelito del Estado por el que se le impone responsabilidad extracontractual es haber hecho perder a las víctimas una oportunidad, que no es posible saber si habrían efectivamente aprovechado, y no haber causado su muerte. Por lo tanto, el rigor técnico debería llevar a los tribunales a otorgar una indemnización por el daño moral correspondiente, si se estima procedente en el caso concreto, a la pérdida de la oportunidad de sobrevivir a la catástrofe, y su medida debería ser objeto de una justificación razonada de parte del tribunal respectivo, porque resulta bastante discutible que el monto de una indemnización por el daño moral sufrido por la muerte de un familiar sea igual al de aquella originada en la pérdida de la oportunidad de sobrevivir.

\section{CONCLUSIÓN}

A la luz de lo que he expuesto como resultado del análisis de este grupo de sentencias que ha empleado la doctrina de la pérdida de una oportunidad 
para resolver juicios indemnizatorios por el fallecimiento de personas como consecuencia del tsunami de febrero de 2010, cabe preguntarse por qué razón o razones nuestros tribunales han utilizado esta doctrina en términos que, sin duda, parecen no del todo satisfactorios a la luz de la estricta teoría. Mi opinión al respecto, admitiendo que tras ella existe un importante componente especulativo, se inclina por entender que existen dos posibles explicaciones. Una primera posibilidad es suponer que existe algún grado de confusión conceptual en la jurisprudencia acerca de lo que es la pérdida de oportunidad. No se trata de una suposición descabellada si consideramos que la teoría de la pérdida de la oportunidad es de aplicación relativamente reciente por nuestros tribunales y que la doctrina civil nacional nunca le prestó especial atención sino hasta hace muy pocos años atrás. ${ }^{51} \mathrm{Si}$ a esto adicionamos que en el derecho comparado la pérdida de la chance sigue siendo objeto de estudios y análisis profundos y de gran calidad debido a las complejidades que ofrece, parece que no es conveniente mostrarse excesivamente severo con los sentenciadores al momento de reprocharles los errores en que puedan incurrir en la implementación local de esta teoría. De hecho, ya es bastante meritorio que en nuestro ordenamiento jurídico los jueces estén abandonando los históricos recelos que impedían su definitiva incorporación a nuestro ordenamiento jurídico.

Sin perjuicio de lo atendible que me parece la anterior explicación, creo que existe una segunda que obedece a una mirada más funcional de la pérdida de la oportunidad, que en caso de ser efectiva demuestra que los tribunales tienen una visión pragmática y alejada de dogmatismos respecto de la misma. Creo que no es necesario poner énfasis en las dramáticas consecuencias materiales y personales del cataclismo del año 2010 y como ellas se proyectan hasta el día de hoy. Ante el sufrimiento de los familiares devastados por la muerte de sus seres queridos y las pérdidas materiales experimentadas en circunstancias en las que tuvo incidencia el insuficiente amparo de los organismos públicos competentes, resulta entendible una mayor sensibilización de los juzgadores al momento de resolver las contiendas y la búsqueda de mejores soluciones para los demandantes, lo que en mi parecer ha quedado plasmado en las sentencias dictadas en los juicios en las diversas etapas que han caracterizado su evolución. Así queda de manifiesto, por ejemplo, cuando los tribunales comenzaron a acoger las pretensiones indemnizatorias haciendo uso, muchas veces en forma bastante

${ }^{51}$ Ríos y Silva, Responsabilidad civil..., cit. (n. 1), pp. 212 y ss. 
discutible, de las presunciones judiciales para establecer la relación de causalidad entre la falta de servicio y el fallecimiento de las víctimas.

Pero lo que considero es la mejor evidencia en orden a que la Corte Suprema busca una solución favorable a las víctimas en los juicios indemnizatorios está en que la Tercera Sala, que revisa todos los recursos de casación contra las sentencias de instancia, ha rechazado las impugnaciones del Fisco contra fallos que establecen su responsabilidad con base en la pérdida de una oportunidad así como aquellas que lo han hecho estableciendo la causalidad entre la falta de servicio y los decesos, criterio que, como he tratado de demostrar en este trabajo, es errado y debería ser objeto de descarte por parte de nuestros tribunales.

La pregunta que surge inmediatamente es: ¿Por qué razón la misma sala de la Corte a cargo de resolver estos recursos rechaza tanto aquellos relativos a sentencias que entienden que el daño unido causalmente a la falta de servicio es la pérdida de una oportunidad como aquellos en que ese daño es la muerte de las víctimas? En rigor, la incoherencia es profunda y los resultados son seriamente reprochables desde un punto de vista teórico. Creo que la razón que mejor explica esto es que la Corte Suprema no ha querido en estos casos cuestionar fallos que resultan favorables a los familiares de las víctimas y ha evitado entrar en análisis tan estrictos desde el punto de vista de la dogmática para privilegiar soluciones más sensibles al dolor que aquellos han sufrido. Solo han sido dejados de lado casos en que la evidencia en contra de los actores ha sido especialmente contundente, como ocurrió en los juicios que forman parte de la que he llamado la primera etapa del curso evolutivo de estos juicios.

En consecuencia, me parece claro que los tribunales en nuestro país han asumido una postura pragmática y funcional en torno a este tema, lo que se extiende al tratamiento de la pérdida de la oportunidad en estos juicios. ${ }^{52}$ Ello explica que los sentenciadores hayan buscado fundamentar de una manera jurídicamente más certera la calificación jurídica del daño como la pérdida de una oportunidad para las víctimas, aun cuando no hayan entrado frontalmente en la discusión de la calificación jurídica de aquella. Por idéntica razón es que las sentencias no contienen un trabajo acabado en el cálculo de las indemnizaciones acorde a criterios derivados del valor de la oportunidad, sino que se otorgan montos equivalentes a lo que los tribunales

\footnotetext{
${ }^{52}$ A similar conclusión llega VAN DAM cuando hace una visión comparativa general de la situación en Europa de la pérdida de una oportunidad. VAN DAM, cit. (n. 2), p. 342.
} 
parecen entender como el daño moral total que corresponde percibir a los demandantes, lo que es un error tanto cualitativo como cuantitativo en el análisis de la oportunidad perdida por las víctimas.

\section{BIBLIOGRAFÍA CITADA}

\section{A) Doctrina}

Alessandri, Arturo, De la responsabilidad extra-contractual en el derecho civil chileno, Editorial Jurídica Ediar - Conosur, Santiago, 1983, 2a edición, T. I.

Alpa, Guido, La Responsabilidad Civil. Parte General, Ediciones Legales, Lima, 2016, Vol. 1.

Arcos VieIrA, María Luisa, Responsabilidad Civil: Nexo Causal e Imputación Objetiva en la Jurisprudencia, Thomson Aranzadi, Cizur Menor, 2005.

Barcellona, Mario, Trattato della Responsabilitá Civile, UTET Giuridica, Torino, 2011.

BARros, Enrique, Tratado de responsabilidad extracontractual, Editorial Jurídica de Chile, 2006.

Deakin, Simon; Johnston, Angus; Markesinis, Basil, Tort Law, Oxford University Press, Oxford, 2013, 7a edición.

Green, Sarah, Causation in Negligence, Hart Publishing, Oxford, 2015.

Jourdain, Patrice, Les principes de la responsabilitè civile, Dalloz, 2007.

Medina Alcoz, Luis, La Teoría de la Pérdida de Oportunidad, Thomson Civitas, Cizur Menor, 2007.

Medina Alcoz, Luis, La Responsabilidad Proporcional como Solución a la Incertidumbre Causal, Thomson Reuters - Civitas, Cizur Menor, 2018.

MunitA, Renzo, "La pérdida de una chance. Notas desde una perspectiva comparada", Actualidad Jurídica, 2013, N 28 (julio), pp. 395-441.

Nolan, Donal, "Causation and the goals of tort law", en: Robertson, A.; Wu, Tang H. (Eds.), The Goals of Private Law, Hart Publisher, Oxford, 2009, pp. 165-190.

Ríos, Ignacio, “QQuién carga con el peso de la incertidumbre causal?”, en Vidal, Á.; Severín, G.; Mejías, C. (Eds.), Estudios de Derecho Civil X, Thomson Reuters, Santiago, 2014, pp. 861-871.

Ríos, Ignacio; SiLva, Rodrigo, Responsabilidad civil por pérdida de la oportunidad, Editorial Jurídica de Chile, Santiago, 2014.

Ríos, Ignacio; Silva, Rodrigo, "La teoría de la pérdida de la oportunidad según la Corte Suprema", Revista de Derecho. Escuela de Postgrado, 2015, N 7, pp. $165-178$. 
Steel, Sandy, Proof of Causation in Tort Law, Cambridge University Press, Cambridge, 2015, pp. 339-369

TAPIA, Mauricio, "Pérdida de una chance: ¿Un perjuicio indemnizable en Chile?", en Elorriaga, Fabián (Coord.), Estudios de Derecho Civil VII, Abeledo Perrot, Thomson Reuters, Santiago, 2012, pp. 645-674.

TAPIA, Mauricio, "Pérdida de una chance. $\mathrm{Su}$ indemnización en la jurisprudencia chilena", Revista de Derecho. Escuela de Postgrado, 2012, № 2 , pp. 251-264.

TurTon, Gemma, Evidential Uncertainty in Causation in Negligence, Hart Publishing, Oxford, 2016.

VAn Dam, Cees, European Tort Law, Oxford University Press, Oxford, 2013, 2a edición.

Vicente Domingo, Elena, "El Daño”, en: Busto Lago, José M.; Reglero, L. Fernando (Coords.), Lecciones de Responsabilidad Civil, Thomson Reuters Aranzadi, Cizur Menor, 2013, pp. 81-103.

Viney, Genevieve; Jourdain, Patrice, Traité de Droit Civil. Les Conditions de la Responsabilité, L.G.D.J, París, 1998, $2^{a}$ edición.

Weinrib, Ernest, "Causal Uncertainty", Oxford Journal of Legal Studies, 2016, vol. 36, $\mathrm{N}^{\circ} 1$, pp. 135-164.

\section{B) Jurisprudencia citada}

Corte Suprema, 20 de enero de 2011, rol No 2074-2009.

Corte Suprema, 23 de enero de 2013, rol N 1250-2012.

Corte Suprema, 18 de diciembre de 2013, rol N 1.629-2013.

Corte Suprema, 29 de abril de 2014, rol N 16.885-2013.

Corte Suprema, 29 de abril de 2014, rol N 16.920-2013.

Tercer Juzgado Civil de Concepción, 20 de octubre de 2015, rol № 1.325 2014.

Tercer Juzgado Civil de Concepción, 30 de octubre de 2015, rol № 1.098 2014.

Vigésimo Segundo Juzgado Civil de Santiago, 27 de abril de 2016, rol C-21.111-2013.

Corte Suprema, 7 de junio de 2016, rol No 32.262-2015.

Corte Suprema, 4 de octubre de 2016, rol N² 24.306-2016.

Corte de Apelaciones de Concepción, 5 de octubre de 2016, rol № 301-2016.

Corte de Apelaciones de Concepción, 18 de octubre de 2016, rol N 70-2016.

Corte de Apelaciones de Santiago, 18 de enero de 2017, rol № 8013-2016.

Corte de Apelaciones de Talca, 8 de junio de 2017, rol № 1.304-2016.

Corte Suprema, 27 de julio de 2017, rol N 68.818-2016. 
Corte Suprema, 31 de julio de 2017, rol No 88.986-2016.

Corte Suprema, 28 de agosto de 2017, rol N 97.661-2016.

Corte Suprema, 9 de noviembre de 2017, rol N 12.169-2017.

Corte Suprema, 16 de noviembre de 2017, rol N 4.658-2017.

Corte de Apelaciones de Talca, 20 de noviembre de 2017, rol № 1.899-2016.

Corte Suprema, 21 de noviembre de 2017, rol N 100.695-2016.

Corte Suprema, 12 de diciembre de 2017, rol N 172-2017.

Corte Suprema, 29 de diciembre de 2017, rol N 97.668-2016.

Corte Suprema, 17 de enero de 2018, rol N 5.094-2017.

Corte Suprema, 26 de marzo de 2018, rol N 10.165-2017.

Corte Suprema, 17 de abril de 2018, rol No 18.225-2017.

Corte Suprema, 28 de junio de 2018, rol No 31.757-2017.

Corte Suprema, 3 de octubre de 2018, rol N 42.539-2017.

Corte Suprema, 8 de noviembre de 2018, rol N 871-2018.

Corte Suprema, 4 de diciembre de 2018, rol N 45.305-2017.

Corte Suprema, 21 de enero de 2019, rol N 40.166-2017.

Corte Suprema, 18 de marzo de 2019, rol N 4185-2018. 